\title{
Stabilization of Silver Nanoparticles with a Dithiocarbamate Ligand and Formation of Nanocomposites by Combination with Polythiophene Derivative Nanoparticles
}

\author{
Paris Jonathan Reynoso-García, ${ }^{1}$ Marisol Güizado-Rodríguez $\mathbb{D},{ }^{1}$ Victor Barba $\left(\mathbb{D},{ }^{2}\right.$ \\ Gabriel Ramos-Ortiz ${ }^{(D}{ }^{3}$ and Hugo Martínez-Gutiérrez ${ }^{4}$ \\ ${ }^{1}$ Centro de Investigación en Ingeniería y Ciencias Aplicadas (CIICAp)-IICBA, Universidad Autónoma del Estado de Morelos (UAEM), \\ Av. Universidad No. 1001, Col. Chamilpa, C.P. 62209, Cuernavaca, MOR, Mexico \\ ${ }^{2}$ Centro de Investigaciones Químicas (CIQ)-IICBA, Universidad Autónoma del Estado de Morelos (UAEM), Av. Universidad No. 1001, \\ Col. Chamilpa, C.P. 62209, Cuernavaca, MOR, Mexico \\ ${ }^{3}$ Centro de Investigaciones en Óptica A.C., Loma del Bosque No. 115, Col. Lomas del Campestre, C.P. 37150, León, GTO, Mexico \\ ${ }^{4}$ Centro de Nanociencias y Micro y Nanotecnologías (CNMN), Instituto Politécnico Nacional (IPN), Av. Luis Enrique Erro S/N, \\ Unidad Profesional Adolfo López Mateos, Zacatenco, Delegación Gustavo A. Madero, C.P. 07738, Ciudad de México, Mexico
}

Correspondence should be addressed to Marisol Güizado-Rodríguez; marisolguizado@uaem.mx

Received 23 March 2018; Accepted 10 June 2018; Published 1 August 2018

Academic Editor: Mohindar S. Seehra

Copyright (C) 2018 Paris Jonathan Reynoso-García et al. This is an open access article distributed under the Creative Commons Attribution License, which permits unrestricted use, distribution, and reproduction in any medium, provided the original work is properly cited.

\begin{abstract}
Spherical morphology for silver nanoparticles (Ag NPs) stabilized with dithiocarbamate (DTC) by reducing silver nitrate with sodium borohydride was obtained, while the addition of sodium citrate and hydrogen peroxide allowed the formation of silver nanotriangles (Ag NTs). Solutions of bright yellow and blue colors characteristic of both morphologies were observed. UV-vis optical analysis of NPs stabilized with DTC showed a plasmonic absorption band at $393 \mathrm{~nm}$ characteristic for spherical morphology, while two bands were observed at $332 \mathrm{~nm}$ and $762 \mathrm{~nm}$, and a shoulder around $500 \mathrm{~nm}$ for the triangular morphology; with these spectra each morphology was confirmed. In these spectra an absorption band between 250 and $260 \mathrm{~nm}$ confirms the presence of DTC ligand. The stability of the NPs was achieved using an $8.69 \times 10^{-3} \mathrm{mM}$ solution of 4-(ethylaminodithiocarbamate) methylpyridine di- $n$-butyltin (IV) through a transmetallation reaction. Silver nanoparticles (Ag NPs) with spherical morphology of average diameter of $12.7 \pm 1.2 \mathrm{~nm}$ and triangular morphology with $28.9 \pm 0.8 \mathrm{~nm}$ for each side of the triangles were analyzed by high resolution scanning electron microscopy (HR-SEM). UV-vis spectra also showed the stability of NPs with DTC for more than three months. A copolymer derived of 3-hexylthiophene with (E)-2-(ethyl(4-((4-nitrophenyl) diazenyl) phenyl) amino) ethyl 2-(thiophen-3-yl) acetate (PA) was tested to get polymer NPs by reprecipitation method using THF/water systems. PA Polymer NPs having average diameter of $9.0 \pm 1.7 \mathrm{~nm}$ were found. By quick and easy procedure, the formation of nanocomposite (NC) of spherical Ag NPs and PA polymer NPs was reached. This NC could be used as imaging agent, electrochemical biosensor, and photonic and optoelectronic device materials.
\end{abstract}

\section{Introduction}

New methodologies have been developed for the synthesis of NPs in order to obtain specific size and shape which in turn defines its applications field. For example, the surface plasmon resonance (SPR) of NPs has been studied for its potential applications in chemistry, optics, magneto-optics, photonics, nanoengineering, and biosensors, among others $[1,2]$.

The interest in synthesizing metallic NPs functionalized with a protective monolayer of some binder grew exponentially due to the numerous nanotechnology applications such as bactericidal agents, because of their antibacterial nature, formation of metallic nanostructures as hybridized 
plasmonic modes in nanoscale metal shells, biological applications, and its use in the surface-enhanced Raman spectroscopy [3-15]. Nowadays, the field of plasmonics has emerged for the development of optoelectronic devices at the nanometric scale, sensors, and biosensors: photovoltaic devices, surface plasmon enhanced light emitting diodes, optical emitters, plasmon focusing, nanoscale waveguiding, and nanoscale optical antennas, among others $[16,17]$.

As the semiconductors, the intrinsic properties of metallic nanostructures can be modified through the control of its size, shape, composition, crystallinity, and structure. The interaction of UV radiation with the silver NPs produces oscillations in the superficial layer of the conduction electrons causing a surface plasmon. The latter results in an absorbance peak due to the surface plasmon resonance; free electrons on the surface of the NP interact with UV radiation resulting in energy absorption. Frequency and intensity of the resonance are highly dependent on the particle size, morphology, and the dielectric function of the surrounding environment. Typical peak of the surface plasmon resonance for spherical morphologies is found at approximately $400 \mathrm{~nm}$, while for triangular morphology it is found at two bands (331 and 754 , respectively) confirming the silver NPs formation [18, 19].

A clear example is the synthesis of gold NPs coated with alkylthiols or dithiocarbamates [20]. This protective layer is necessary in order to prevent the aggregation of particles when suspended in a liquid; moreover, it can act as a binding platform for molecules or particles [21]. DTCs have emerged as an alternative to the thiols for gold and silver surface functionalization. DTCs bond is stronger than the thiols to gold and also are compatible with a wide range of environmental conditions and are easier to synthesize by condensation of amines with $\mathrm{CS}_{2}$ in basic conditions [22, 23].

Polymer NPs present easy synthesis, tuneable properties, and less toxicity and more biocompatibility compared to the existing inorganic nanoparticles makes these materials highly attractive in the material choice [24]. Conductive polymer nanocomposites is a type of nanocomposite in which the conductive polymer serves as the matrix while other components at the nanoscale serve as the nanofiller, combining the synergistic effects of both components. Polythiophene (PTh) and their derivatives are one of the most popular studied conducting polymers while the most widely incorporated nanofillers consist of conducting nanostructures such as carbon nanotubes, graphene, metals, and insulating ceramic nanostructures, molecular species such as metallophthalocyanines, or biologically active components such as enzymes, antibodies, and antigens $[25,26]$.

Due to the outstanding electronic, optical, and mechanical properties, high structural stabilities, easy processing features, and economical synthesis costs, conducting polymers and their derivatives as conductive polymer nanocomposites are widely used in various optoelectronic devices [27]. It is possible to enhance their characteristics, achieve some new functionalities, and improve their performances by designing, tailoring, and modifying their structure compositions and morphologies; for instance, conductive polymer-based nanocomposites have been widely applied to fabricate the biosensors, because of their outstanding properties such as excellent electrocatalytic activity, high conductivity, and strong adsorptive ability compared to conventional conductive polymers [28].

In this article, spherical and triangular silver nanoparticles were synthesized by reducing silver nitrate with sodium borohydride, while adding sodium citrate and hydrogen peroxide; the triangular morphology was obtained. These nanoparticles were characterized by UV-vis and HR-SEM. Both morphologic NPs were stabilized using a dithiocarbamate tin complex by transmetallation reaction. Additionally, spherical PA polythiophene derivative NPs were obtained by reprecipitation method using THF/water systems. A light emission study for these conjugated polymer NPs was carried out. A quick and easy procedure to obtain nanocomposites formed from spherical Ag NPs stabilized with DTC and PA polymer NPs retaining its morphology was reached.

\section{Experimental}

2.1. Materials and Equipment. Silver nitrate $99.6 \%$, sodium borohydride $98.7 \%$, and sodium citrate $99.5 \%$ were acquired from Fermont, hydrogen peroxide 30\% was bought from Golden Bell, and deionized water purchased from Hycel. UV-vis spectra were measured with an Instruments Genesys 10 Spectrophotometer, and the fluorescence spectra were determined with a Luminescence LS55 Spectrophotometer. Finally, JSM-7800F Field Emission Scanning Electron (HRSEM) was used obtaining micrographs with transmitted and backscattered electrons, analyzed with the ImageJ program.

\subsection{Synthesis of Nanoparticles}

2.2.1. Synthesis of Spherical Silver Nanoparticles. By a typical synthesis of silver nanoparticles, $30 \mathrm{~mL}(0.0643 \mathrm{mmol})$ of $2.14 \mathrm{mM}$ sodium borohydride solution in deionized water was added in a round bottom flask at $10^{\circ} \mathrm{C}$; next $10 \mathrm{~mL}$ $(0.00946 \mathrm{mmol})$ of silver nitrate $0.946 \mathrm{mM}$ solution was slowly added, one drop per second. The reaction was stirred to 250-300 rpm; after the complete addition the solution changed to bright yellow indicating the presence of $\mathrm{Ag}$ NPs and the solution was left to finish stirring. An excess of sodium borohydride was added to complete reduction of silver nitrate and increase the NPs stability. Finally, the solution was diluted until a final concentration of $4.73 \times$ $10^{-5} \mathrm{M}$ was reached.

\subsubsection{Silver Nanotriangles [29, 30]}

Blue Solution. The silver nanotriangles were synthesized by reducing silver nitrate $(0.14 \mathrm{mM}, 50 \mathrm{~mL})$ with sodium borohydride $(0.21 \mathrm{M}, 250 \mu \mathrm{L})$ in the presence of sodium citrate (30.2 mM, $3 \mathrm{~mL}$ ) and $120 \mu \mathrm{L}$ of $\mathrm{H}_{2} \mathrm{O}_{2}$ (Golden Bell, 30\%), in this order of addition, under magnetic stirring at room temperature to $1500 \mathrm{rpm}$; physical changes were transparent coloration change to a yellow tone and immediate change to blue tone indicative of the formation of silver nanotriangles (Ag NTs); after that, the reaction was completed, obtaining a final concentration after dilution of $2.65 \times 10^{-5} \mathrm{M}$. 
2.2.3. Stabilization of Spherical and Triangular Silver Nanoparticles with Dithiocarbamate Derivative (DTC-Sn- $n B U)$. A methanol solution $(1.74 \mathrm{mM})$ of 4 -(ethylaminodithiocarbamate) methylpyridine di-n-butyltin (IV) (DTC-Sn$n \mathrm{Bu}$ ) was prepared. Tin derivative was synthesized as reported in the literature [31]. This solution was diluted in methanol to obtain an $8.69 \times 10^{-3} \mathrm{mM}$ solution; 10 to $50 \mu \mathrm{L}$ of final solution (systems labeled as 10 to 50 DTC) was added to diluted solutions of spherical Ag NPs (9 mL, 4.26 $\left.\times 10^{-4} \mathrm{mmol}\right)$ or triangular Ag NPs $\left(9 \mathrm{~mL}, 2.38 \times 10^{-4} \mathrm{mmol}\right)$. The addition was carried out at room temperature and the systems were under constant stirring for $5 \mathrm{~min}$ at $200 \mathrm{rpm}$. Systems were completed to $10 \mathrm{~mL}$ with water. With this method yellow spherical or blue triangular silver NPs stabilized with dithiocarbamate were obtained.

2.2.4. Polymer NPs. Polymer NPs were obtained using a polymer derived of 3-hexylthiophene with (E)-2-(ethyl (4-((4nitrophenyl) diazenyl) phenyl) amino) ethyl 2-(thiophen-3yl) acetate (PA), which was synthesized by our research group and is already reported [32]. A reprecipitation procedure was employed adding a THF solution of PA polymer to another solvent (water) where the polymer is insoluble. A solution of $0.03 \mathrm{mg} / \mathrm{mL}$ of PA polymer in THF was prepared and added in different volumes ( 1 to $9 \mathrm{~mL}$ ) to water (9 to $1 \mathrm{~mL}$ ) systems. The addition of PA solution to water systems was about one drop per second with constant stirring (150 rpm); the stirring continued for $10 \mathrm{~min}$. After that, the minimagnet was removed and the systems were completed with the same volume system (1:9 to $9: 1, \mathrm{THF}$ : water) to get $10 \mathrm{~mL}$ using volumetric flasks. This allowed obtaining PA polymer NPs; the system 2:8 (THF: water) was the best, which has a concentration of $6 \times 10^{-3} \mathrm{mg} / \mathrm{mL}, 1.38 \times 10^{-6} \mathrm{M}$.

2.2.5. Nanocomposite Formed by Silver and PA Polymer NPs. $5 \mathrm{~mL}$ of spherical or triangular Ag NPs (10 DTC system) mentioned in Section 2.2.3 was combined with $5 \mathrm{~mL}$ of PA polymer NPs system 2: 8 described above in Section 2.2.4.

\section{Results and Discussion}

A yellow solution is obtained by the reduction of silver ions when $\mathrm{NaBH}_{4}$ was added. The UV-vis measurements exhibited a single peak at $390 \mathrm{~nm}$, Figure 1, independent of the NP concentration. Spectrum is in good agreement with results and predictions for spherical Ag NPs of sizes between $3 \mathrm{~nm}$ and $20 \mathrm{~nm}[1,2]$.

Several volumes of DTC-Sn- $n$ Bu solution $(10-50 \mu \mathrm{L}, 8.69$ $\left.\times 10^{-6} \mathrm{M}\right)$ were added as stabilizer of Ag NPs, with spherical morphology $\left(4.26 \times 10^{-5} \mathrm{M}\right)$. A peak at $\lambda_{\max }=393 \mathrm{~nm}$ was observed (Figure 2(a)). An absorption band of $250 \mathrm{~nm}$ was probably from DTC ligand. It was of interest to investigate whether neutral DTC-Sn- $n \mathrm{Bu}$ complexes could be used as alternative synthons to produce dithiocarbamate stabilized NPs, as a zinc (II) dithiocarbamate complex has been used for this purpose [23]. EDX analysis of particles did not show the presence of tin atoms; this observation confirms that during particle formation tin atoms are not present at the particle

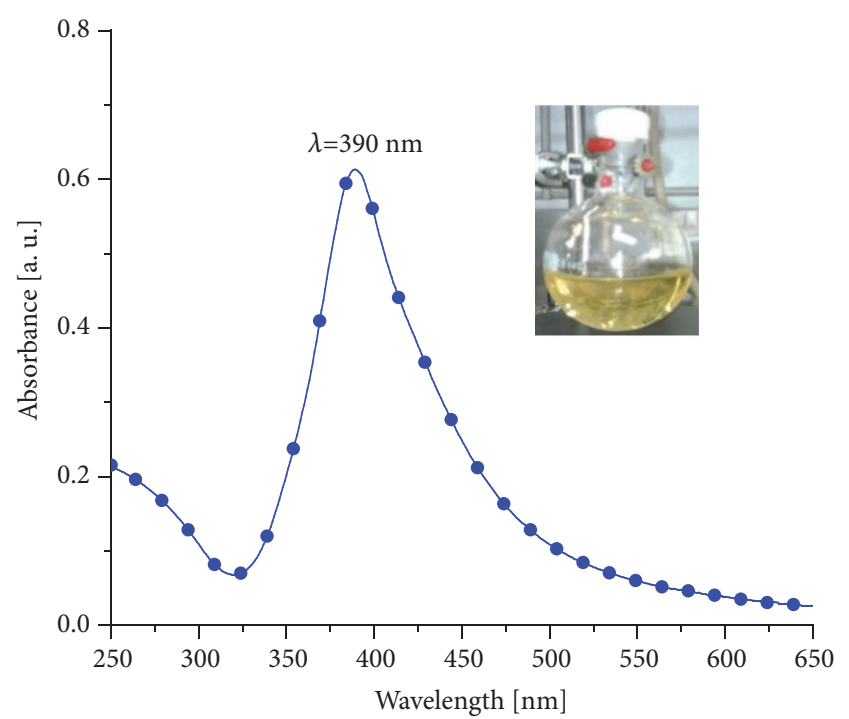

Figure 1: UV-vis spectrum of spherical Ag NPs.

core and that presumably tin cation exists in a solvated form in the capping ligand shell preserving electroneutrality with the dithiocarbamate anion, Figure 2(b).

The particle dimensions were evaluated by HR-SEM measurements, where a drop of the nanoparticle solution was spread onto a Carbon Film $300 \mathrm{Mesh} \mathrm{Cu}$. The size distribution for all NPs was fitted to the log-normal distribution with $\mathrm{Do}=$ median particle diameter and $\lambda_{\mathrm{D}}=$ width of the distribution with average particle diameter $\langle\mathrm{D}\rangle$, and standard deviation $\sigma$ [33]. Spherical Ag NPs with an average particle diameter $<\mathrm{D}>$ of $12.7 \pm 1.2 \mathrm{~nm}$ (Figure 3 ) were found.

When the sodium citrate and hydrogen peroxide are added before $\mathrm{NaBH}_{4}$, the solution acquires first a yellow color, but after some minutes the color had changed to blue. UV-vis absorption spectrum clearly reflects the anisotropic shape of Ag NTs. Instead of a single peak around $400 \mathrm{~nm}$ characteristic of spherical particles, three peaks appear at $682 \mathrm{~nm}, 480 \mathrm{~nm}$, and $333 \mathrm{~nm}$. These peaks have been attributed to the in-plane dipole, in-plane quadrupole, and out-of-plane quadrupole plasmon resonances $[29,30]$. In our analysis two bands at $331 \mathrm{~nm}$ and $754 \mathrm{~nm}$, the last one with a shoulder around $500 \mathrm{~nm}$, characteristic of Ag NTs were founded (Figure 4).

Different amounts of DTC-Sn- $n \mathrm{Bu}(10-30 \mu \mathrm{L}, 8.69 \times$ $10^{-6} \mathrm{M}$ ) were also added to the Ag NTs, obtaining bands at $332 \mathrm{~nm}$, with a mild shoulder around $500 \mathrm{~nm}$ and $762 \mathrm{~nm}$, Figure 5. Also, an absorption band of $260 \mathrm{~nm}$ from DTC ligand was observed. SEM-HR analysis showed that the Ag NTs presented an average side size of $28.9 \pm 0.8 \mathrm{~nm}$, Figure 6 .

Through the reprecipitation method using $2: 8$ (THF:water) system, spherical PA polymer NPs were obtained. As an example, the UV-vis spectrum of PA polymer with bands at $255 \mathrm{~nm}$ and $448 \mathrm{~nm}$ and its structure are shown, Figure 7. An average diameter of $9.0 \pm 1.7 \mathrm{~nm}$ for this PA polymer NPs was found, Figure 8.

Emission spectra of PA polymer NPs in several solvent relations are presented in Figures 9(a) and 9(b). In emission spectrum of 2:8 (THF: water) relation, a band at $573 \mathrm{~nm}$ 


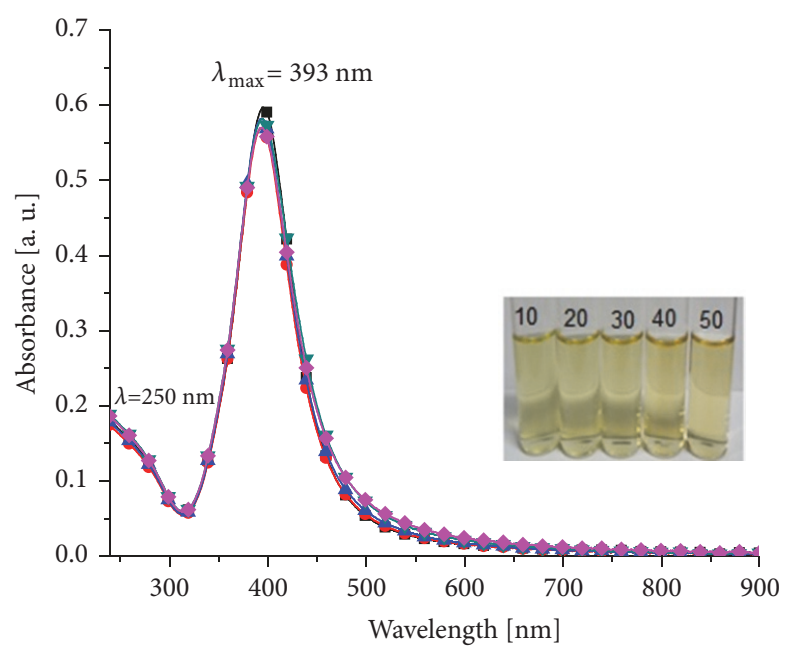

Ag NPs $\left[4.26 \times 10^{-5} \mathrm{M}\right]$

DTC-Sn- $n \mathrm{Bu}\left[8.69 \times 10^{-6} \mathrm{M}, \mu \mathrm{L}\right]$

$$
\begin{array}{ll}
\because-10 & \square-40 \\
\because-20 & \longrightarrow-50
\end{array}
$$

(a)

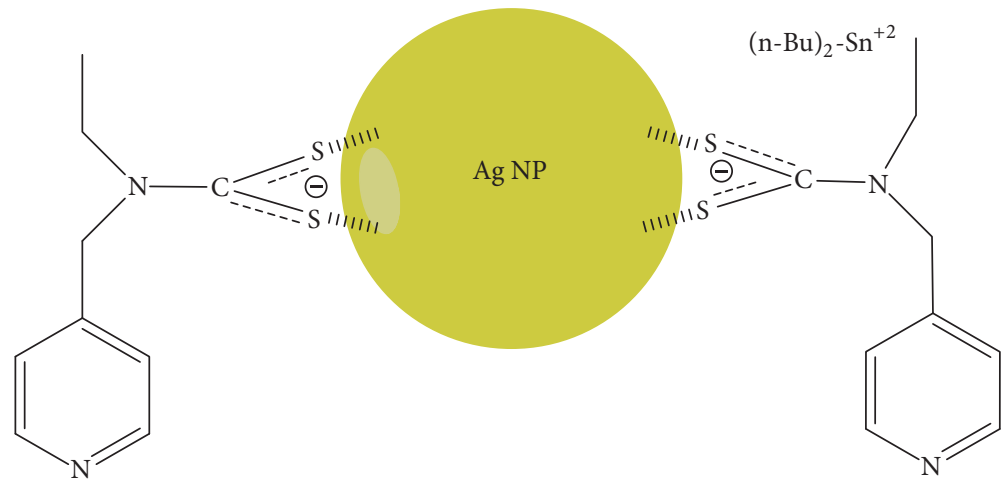

(b)

FIgURE 2: (a) UV-vis spectra of Ag NPs stabilized with DTC-Sn- $n$ Bu; (b) representation of DTC-Sn- $n$ Bu stabilizing Ag NPs.

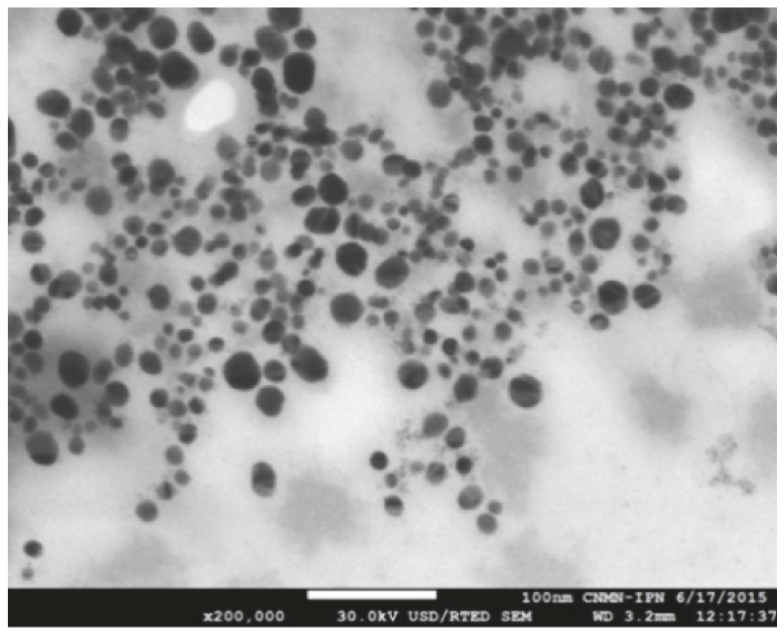

(a)

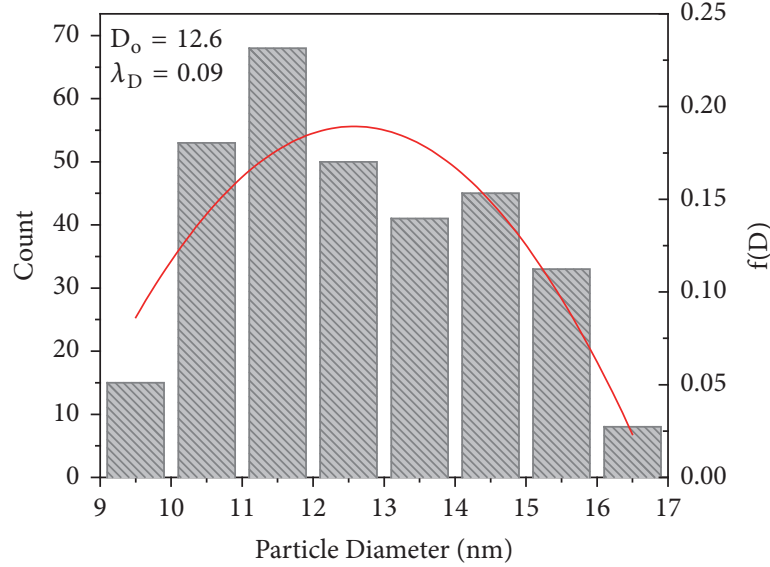

Nrequency 313

(b)

Figure 3: (a) Micrograph of Ag NPs stabilized with DTC-Sn- $n \mathrm{Bu}$; (b) histogram of Ag NPs. 


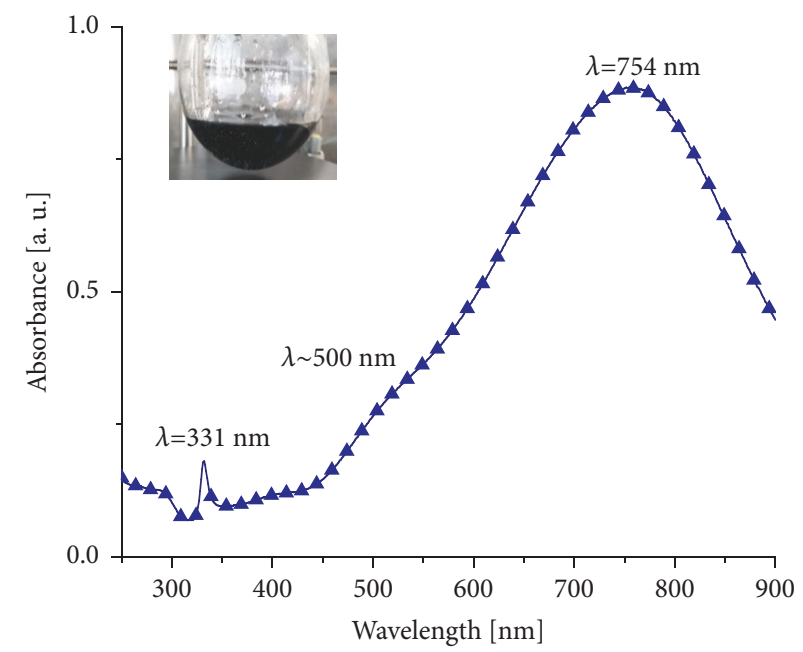

FIGURE 4: UV-vis spectrum of Ag nanotriangles.

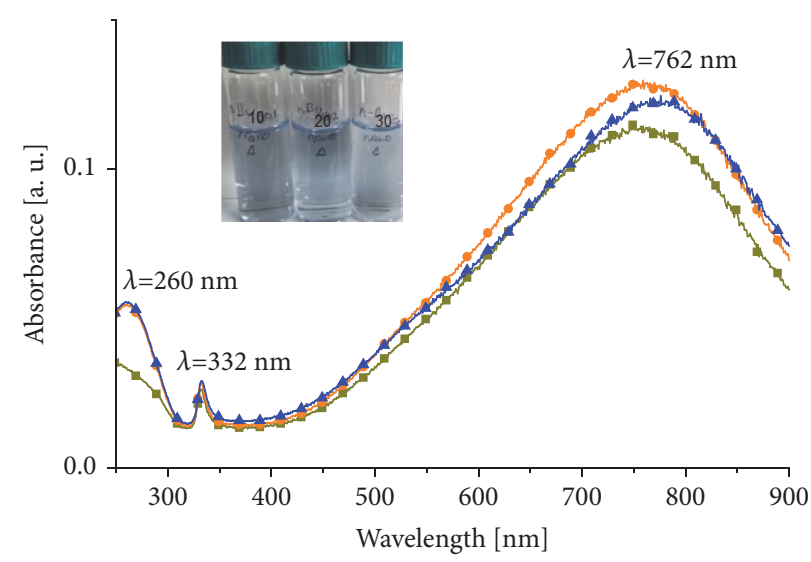

Ag nanotriangles $\left[2.38 \times 10^{-5} \mathrm{M}\right]$
DTC-Sn- $n \mathrm{Bu}\left[8.69 \times 10^{-6} \mathrm{M}, \mu \mathrm{L}\right]$
-10
$\simeq 20$
$\simeq 30$

FIGURE 5: UV-vis spectra of Ag NTs stabilized with DTC-Sn- $n$ Bu.

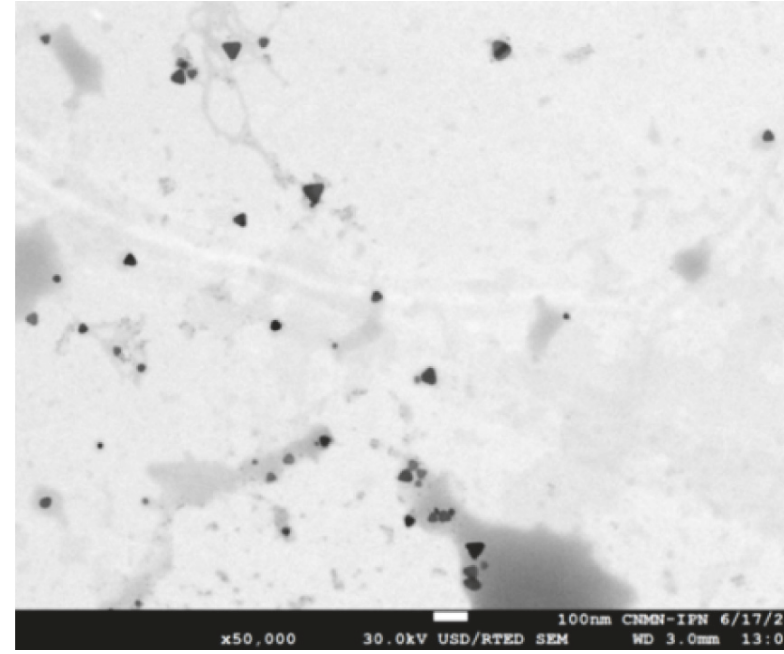

(a)

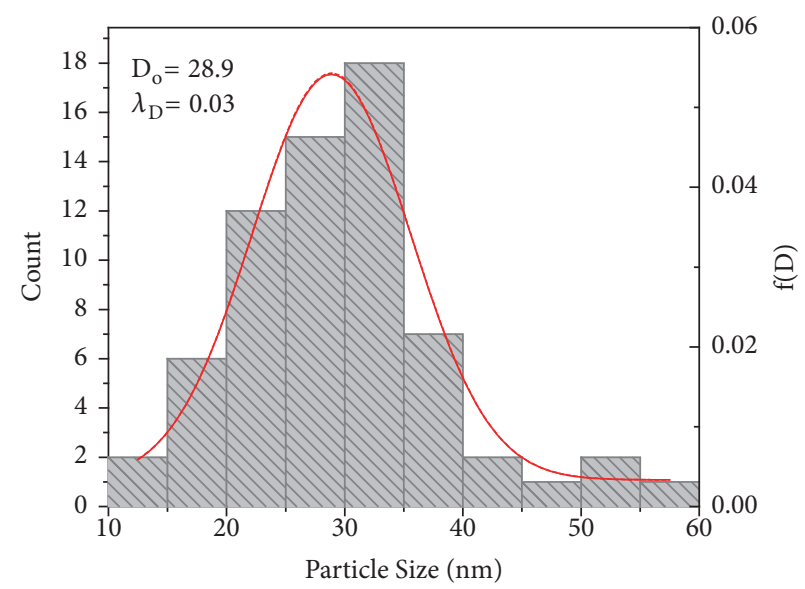

MIV frequency 66

FIGURE 6: (a) SEM-HR micrograph and (b) histogram of Ag nanotriangles stabilized with DTC-Sn- $n \mathrm{Bu}$. 


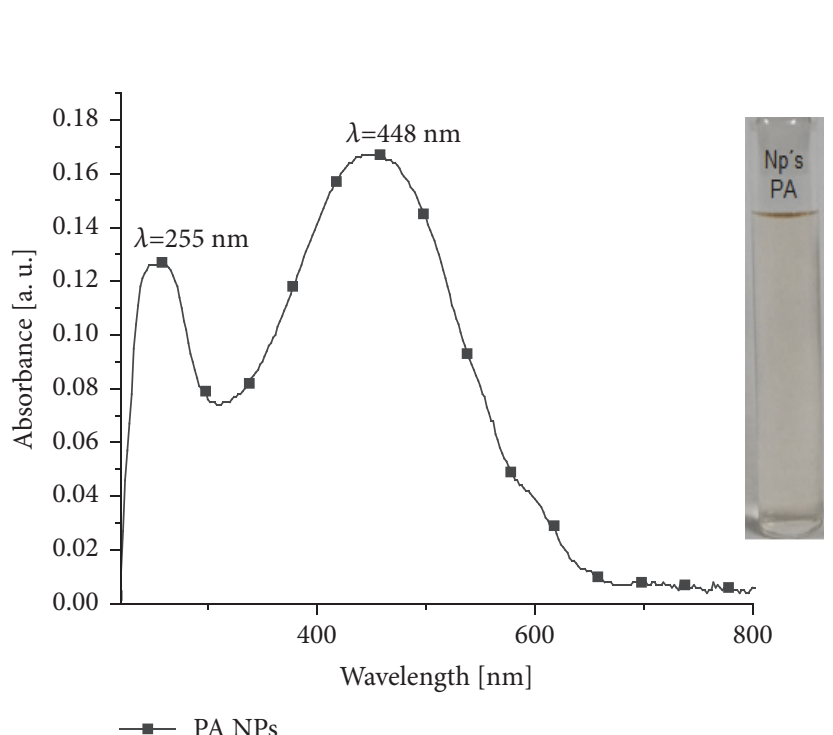

(a)

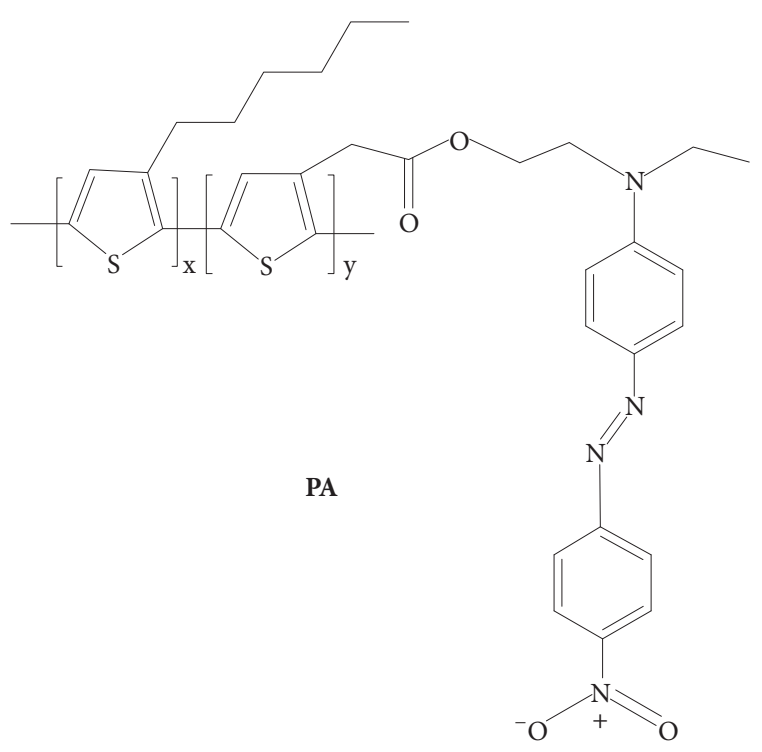

(b)

Figure 7: (a) UV-vis spectrum of PA polymer NPs relation 2:8 THF : water system; (b) structure of PA polymer.

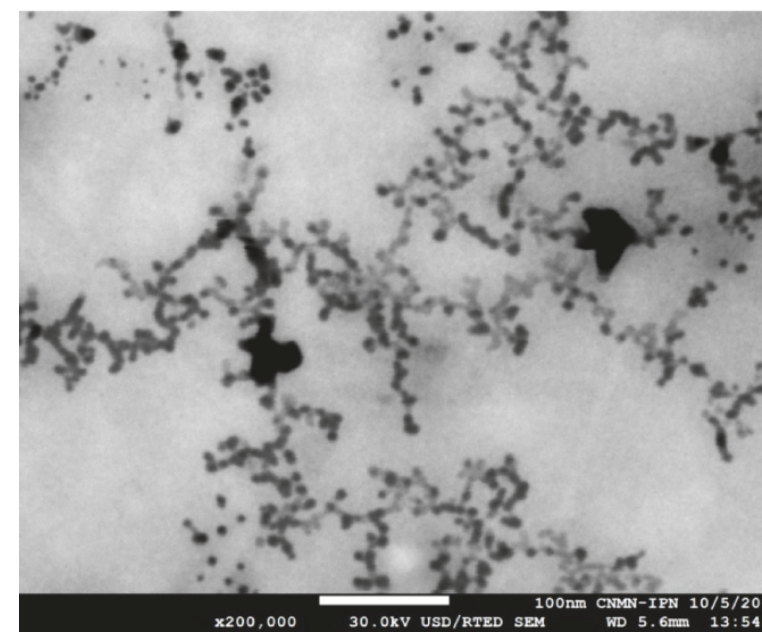

(a)

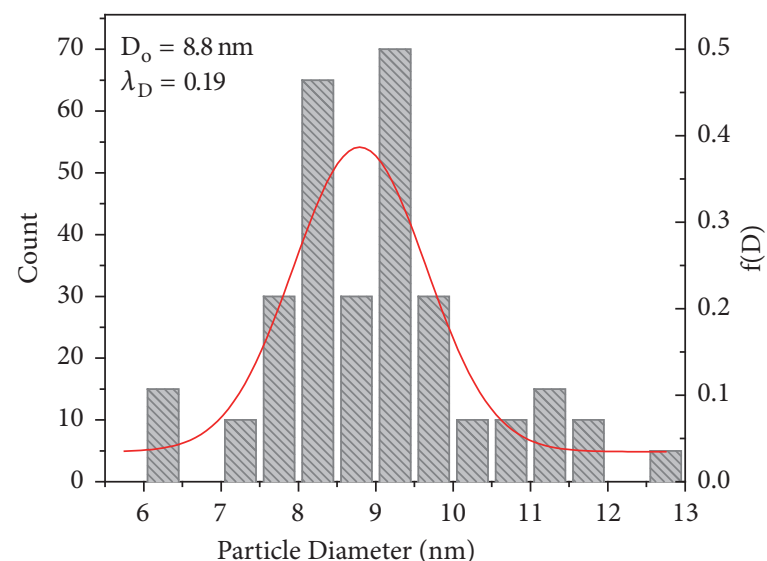

MV Frequency 300

Figure 8: (a) SEM-HR micrograph of PA polymer NPs (x200,000); (b) histogram of PA polymer NPs.

and a shoulder at $617 \mathrm{~nm}$ are observed. The spectra analysis showed two behaviors: a batochromic shift from relations 1:9 to $4: 6$ and from $5: 5$ to $9: 1$. In the spectrum obtained with relation $5: 5$ (THF: water) two bands at $515 \mathrm{~nm}$ and $568 \mathrm{~nm}$ and a shoulder at $620 \mathrm{~nm}$ are found, Figure 9(b).

PA polymer and Ag NPs were combined in a 5:5 relation ( $5 \mathrm{~mL}$ of PA polymer system $2: 8 / 5 \mathrm{~mL}$ of spherical Ag NPs 10 DTC system), Figure 10. Only the spherical Ag NPs retained their morphology when combined with the PA polymer nanoparticles. It is possible to see that the absorption decreased more compared to that caused by dilution (50\%); additionally, the nanocomposite (NC) presented the combination of both absorption bands, $405 \mathrm{~nm}$ and around $500 \mathrm{~nm}$ : one for the plasmonic band absorption of Ag NPs that has a small red shift of $12 \mathrm{~nm}$ and another for PA polymer NPs.
Emission of this $\mathrm{NC}$ was quenched because of the presence of Ag NPs.

The SEM micrographs of the NCs exhibit very visible and well-dispersed nanospherical particles from both structures after the combination, Figure 11. When NPs are analyzed by HR-SEM using transmitted electrons, PA polymer NPs are showed as gray spheres while Ag NPs are presented as darker spheres. If the NPs are analyzed using backscattered electrons, Ag NPs are the brightest.

\section{Conclusions}

An effective methodology was established for the synthesis of silver nanoparticles with spherical morphology with average diameter of $12.7 \pm 1.2 \mathrm{~nm}$ and triangular prisms with side 


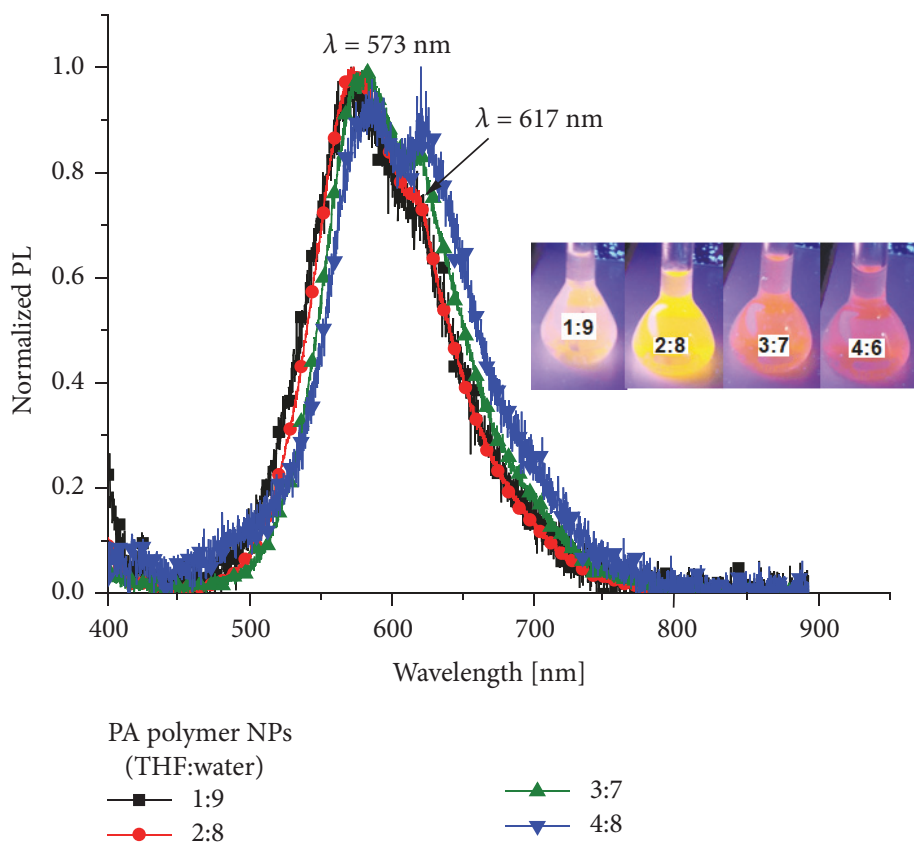

(a)
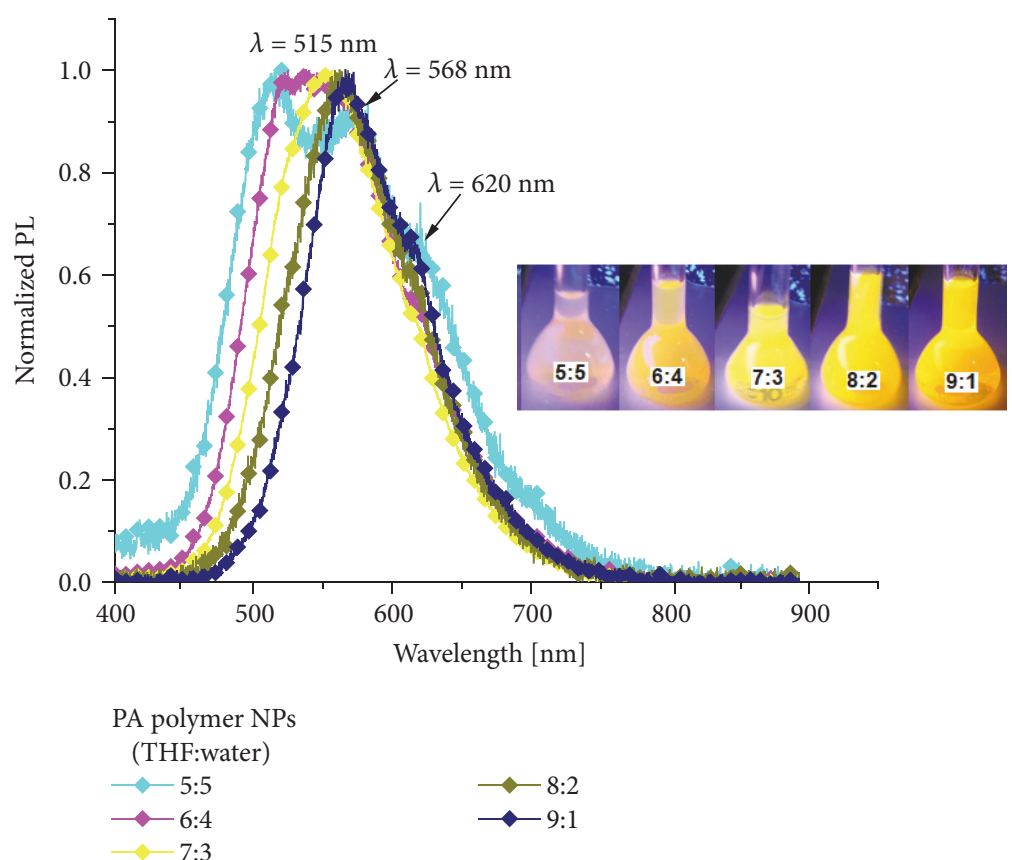

(b)

FIgURE 9: Normalized PL spectra of PA NPs. (a) Relations of 1:9 to 4:6 and (b) 5:5 to 9:1 (THF : water) systems under UV illumination.

size of $28.9 \pm 0.8 \mathrm{~nm}$ using DTC-Sn- $n \mathrm{Bu}$ dithiocarbamate as the protecting ligand through a transmetallation reaction. These Ag NPs at low concentrations are stable for more than three months. The PA polymer NPs with average diameter of $9.0 \pm 1.7 \mathrm{~nm}$ were obtained by the reprecipitation method using $\mathrm{THF} / \mathrm{H}_{2} \mathrm{O}$ system relation $2: 8$. The combination of both systems at specific concentrations gave nanocomposites (NCs); the nanocomposite formed by spherical Ag NPs and PA polymer NPs was the most stable system that retained the spherical morphology of both. These systems could be interesting for applications in the fields of catalysis, biosensing, electronics, and optics. 


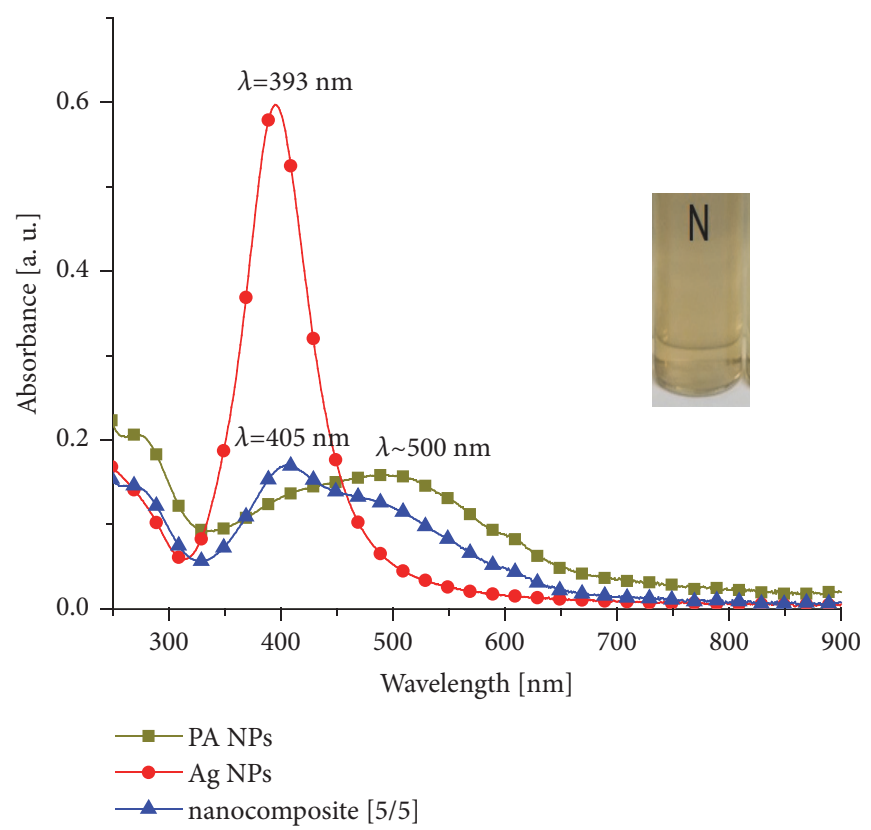

FIGURE 10: UV-vis spectra of NC formed of Ag NPs and PA polymer NPs.

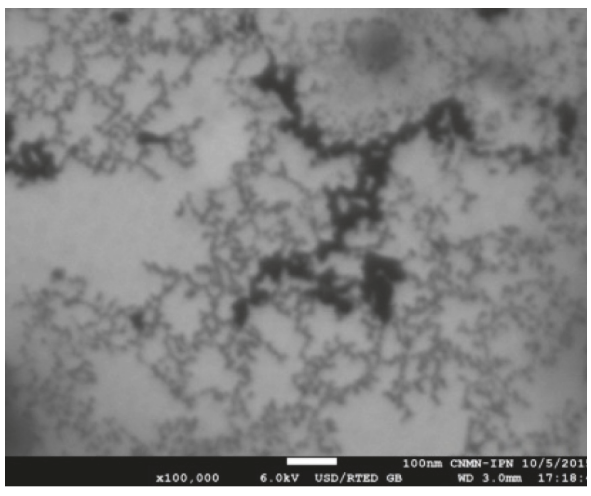

(a)

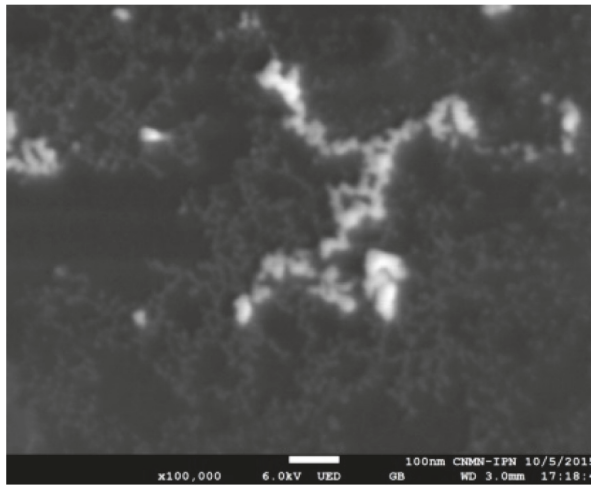

(b)

FIGURE 11: SEM-HR micrography of NCs (x100,000) obtained by (a) transmitted electrons and (b) backscattered electrons.

\section{Data Availability}

The data used to support the findings of this study are included within the article, but if additional information is needed, it is available from the corresponding author upon request.

\section{Conflicts of Interest}

The authors declare that they have no conflicts of interest.

\section{Acknowledgments}

The authors would like to thank CIQ-UAEM for the spectroscopic analysis, and the Laboratory of Spectroscopy at the Optics Research Center for the facilities they generously provided for this work. They also gratefully acknowledge
CONACYT (Grant no. CB2015-257543-Q, CB2010-158098, and supramolecular thematic network Project 281251) for funding the project. In particular, Paris Jonathan ReynosoGarcía is indebted to CONACYT for their scholarship support (Grant no. 359202/248538).

\section{References}

[1] C. Noguez, "Optical properties of isolated and supported metal nanoparticles," Optical Materials, vol. 27, no. 7, pp. 1204-1211, 2005.

[2] C. Noguez, "Surface plasmons on metal nanoparticles: the influence of shape and physical environment," The Journal of Physical Chemistry C, vol. 111, no. 10, pp. 3606-3619, 2007.

[3] A. R. Shahverdi, S. Minaeian, H. R. Shahverdi, H. Jamalifar, and A. Nohi, "Rapid synthesis of silver nanoparticles using culture supernatants of Enterobacteria: a novel biological approach," Process Biochemistry, vol. 42, no. 5, pp. 919-923, 2007. 
[4] V. K. Sharma, R. A. Yngard, and Y. Lin, "Silver nanoparticles: Green synthesis and their antimicrobial activities," Advances in Colloid and Interface Science, vol. 145, no. 1-2, pp. 83-96, 2009.

[5] N. Vigneshwaran, A. A. Kathe, P. V. Varadarajan, R. P. Nachane, and R. H. Balasubramanya, "Biomimetics of silver nanoparticles by white rot fungus, Phaenerochaete chrysosporium," Colloids and Surfaces B: Biointerfaces, vol. 53, no. 1, pp. 55-59, 2006.

[6] M. Tsuji, M. Hashimoto, Y. Nishizawa, M. Kubokawa, and T. Tsuji, "Microwave-assisted synthesis of metallic nanostructures in solution," Chemistry, vol. 11, no. 2, pp. 440-452, 2005.

[7] L. Zhang, Y. Shen, A. Xie, S. Li, B. Jin, and Q. Zhang, "One-step synthesis of monodisperse silver nanoparticles beneath vitamin E Langmuir monolayers," The Journal of Physical Chemistry B, vol. 110, no. 13, pp. 6615-6620, 2006.

[8] B. J. Wiley, Y. Xiong, Z.-Y. Li, Y. Yin, and Y. Xia, "Right bipyramids of silver: a new shape derived from single twinned seeds," Nano Letters, vol. 6, no. 4, pp. 765-768, 2006.

[9] P. Mohanpuria, N. K. Rana, and S. K. Yadav, "Biosynthesis of nanoparticles: technological concepts and future applications," Journal of Nanoparticle Research, vol. 10, no. 3, pp. 507-517, 2008.

[10] Y. Xie, R. Ye, and H. Liu, "Synthesis of silver nanoparticles in reverse micelles stabilized by natural biosurfactant," Colloids and Surfaces A: Physicochemical and Engineering Aspects, vol. 279, no. 1-3, pp. 175-178, 2006.

[11] B. Wiley, Y. Sun, B. Mayers, and Y. Xia, "Shape-controlled synthesis of metal nanostructures: the case of silver," Chemistry, vol. 11, no. 2, pp. 454-463, 2005.

[12] B. Pietrobon, M. McEachran, and V. Kitaev, "Synthesis of sizecontrolled faceted pentagonal silver nanorods with tunable plasmonic properties and self-assembly of these nanorods," ACS Nano, vol. 3, no. 1, pp. 21-26, 2009.

[13] C. M. Cobley, S. E. Skrabalak, D. J. Campbell, and Y. Xia, "Shapecontrolled synthesis of silver nanoparticles for plasmonic and sensing applications," Plasmonics, vol. 4, no. 2, pp. 171-179, 2009.

[14] X. Yang and J. Loos, "Toward high-performance polymer solar cells: the importance of morphology control," Macromolecules, vol. 40, no. 5, pp. 1353-1362, 2007.

[15] L. Lu, A. Kobayashi, K. Tawa, and Y. Ozaki, "Silver nanoplates with special shapes: controlled synthesis and their surface plasmon resonance and surface-enhanced Raman scattering properties," Chemistry of Materials, vol. 18, no. 20, pp. 48944901, 2006.

[16] H. A. Atwater and A. Polman, "Plasmonics for improved photovoltaic devices," Nature Materials, vol. 9, no. 3, pp. 205213, 2010.

[17] S. P. Chandran, M. Chaudhary, R. Pasricha, A. Ahmad, and M. Sastry, "Synthesis of gold nanotriangles and silver nanoparticles using Aloe vera plant extract," Biotechnology Progress, vol. 22, no. 2, pp. 577-583, 2006.

[18] Y. Xia and N. J. Halas, "Shape-controlled synthesis and surface plasmonic properties of metallic nanostructures," MRS Bulletin, vol. 30, no. 5, pp. 338-348, 2005.

[19] A. R. Siekkinen, J. M. McLellan, J. Chen, and Y. Xia, "Rapid synthesis of small silver nanocubes by mediating polyol reduction with a trace amount of sodium sulfide or sodium hydrosulfide," Chemical Physics Letters, vol. 432, no. 4-6, pp. 491-496, 2006.

[20] J. Cookson and P. D. Beer, "Exploiting the dithiocarbamate ligand in metal-directed self-assembly," Dalton Transactions, no. 15, pp. 1459-1472, 2007.

[21] K. Chen and H. D. Robinson, "Robust dithiocarbamateanchored amine functionalization of Au nanoparticles," Journal of Nanoparticle Research, vol. 13, no. 2, pp. 751-761, 2011.
[22] M. C. Tong, W. Chen, J. Sun, D. Ghosh, and S. Chen, "Dithiocarbamate-capped silver nanoparticles," The Journal of Physical Chemistry B, vol. 110, no. 39, pp. 19238-19242, 2006.

[23] M. S. Vickers, J. Cookson, P. D. Beer, P. T. Bishop, and B. Thiebaut, "Dithiocarbamate ligand stabilised gold nanoparticles," Journal of Materials Chemistry, vol. 16, no. 2, pp. 209-215, 2006.

[24] D. Tuncel and H. V. Demir, "Conjugated polymer nanoparticles," Nanoscale, vol. 2, no. 4, pp. 484-494, 2010.

[25] C. Zhan, G. Yu, Y. Lu, L. Wang, E. Wujcik, and S. Wei, "Conductive polymer nanocomposites: a critical review of modern advanced devices," Journal of Materials Chemistry C, vol. 5, no. 7, pp. 1569-1585, 2017.

[26] D. W. Hatchett and M. Josowicz, "Composites of intrinsically conducting polymers as sensing nanomaterials," Chemical Reviews, vol. 108, no. 2, pp. 746-769, 2008.

[27] U. Mehmood, A. Al-Ahmed, and I. A. Hussein, "Review on recent advances in polythiophene based photovoltaic devices," Renewable \& Sustainable Energy Reviews, vol. 57, pp. 550-561, 2016.

[28] M. Naseri, L. Fotouhi, and A. Ehsani, "Recent progress in the development of conducting polymer-based nanocomposites for electrochemical biosensors applications: a mini-review," The Chemical Record, vol. 18, no. 6, pp. 1-21, 2018.

[29] V. Torres, M. Popa, D. Crespo, and J. M. Calderón Moreno, "Silver nanoprism coatings on optical glass substrates," Microelectronic Engineering, vol. 84, no. 5-8, pp. 1665-1668, 2007.

[30] G. Si, W. Shi, K. Li, and Z. Ma, "Synthesis of PSS-capped triangular silver nanoplates with tunable SPR," Colloids and Surfaces A: Physicochemical and Engineering Aspects, vol. 380, no. 1-3, pp. 257-260, 2011.

[31] V. Barba, B. Arenaza, J. Guerrero, and R. Reyes, "Synthesis and structural characterization of diorganotin dithiocarbamates from 4-(ethylaminomethyl)pyridine," Heteroatom Chemistry, vol. 23, no. 5, pp. 422-428, 2012.

[32] R. M. A. De La Garza-Rubí, M. Güizado-Rodríguez, D. Mayorga-Cruz et al., "Polythiophene derivative functionalized with disperse red 1 chromophore: Its third-order nonlinear optical properties through Z-scan technique under continuous and femtosecond irradiation," Optical Materials, vol. 46, pp. 366-372, 2015.

[33] K. L. Pisane, E. C. Despeaux, and M. S. Seehra, "Magnetic relaxation and correlating effective magnetic moment with particle size distribution in maghemite nanoparticles," Journal of Magnetism and Magnetic Materials, vol. 384, pp. 148-154, 2015. 

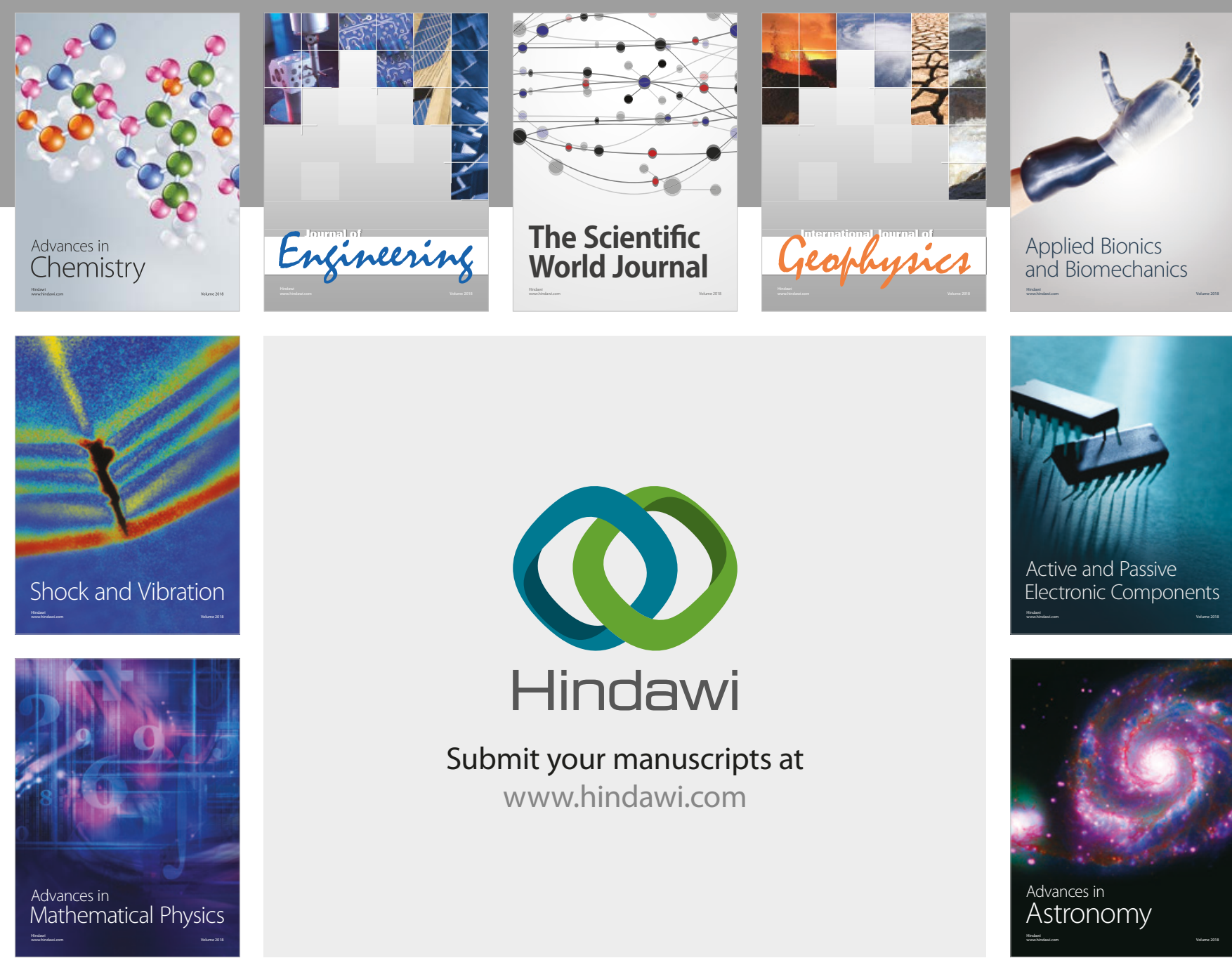

Submit your manuscripts at

www.hindawi.com

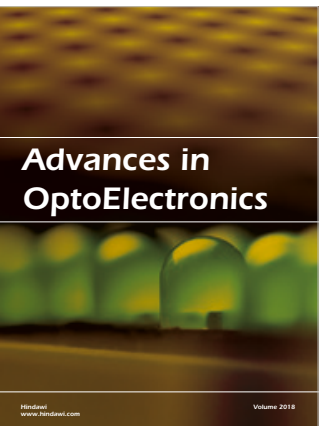

\section{Rotcting Machinery}
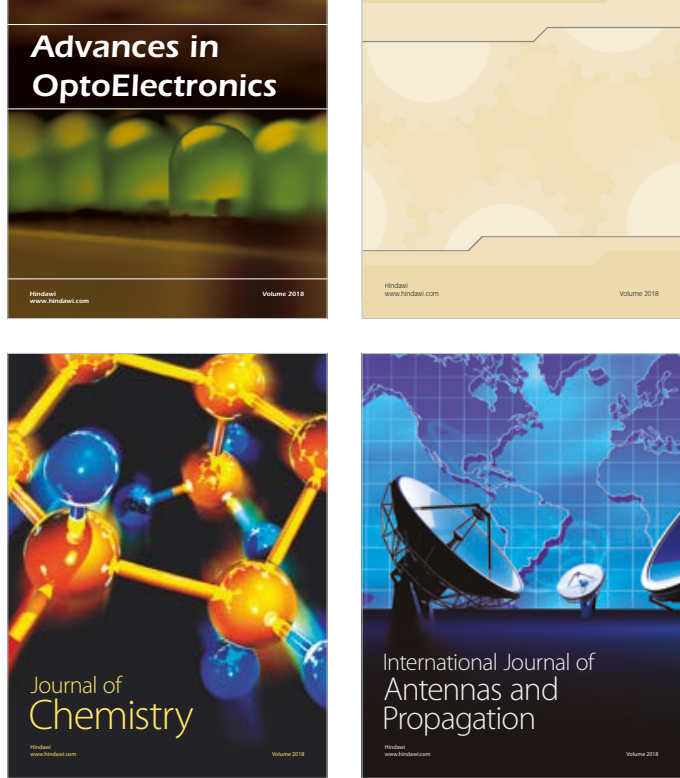

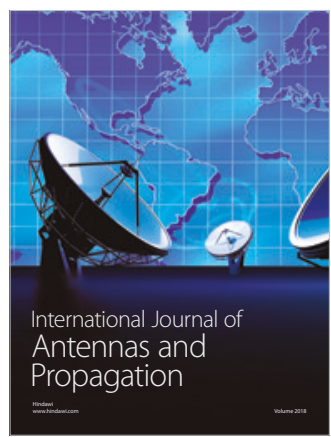

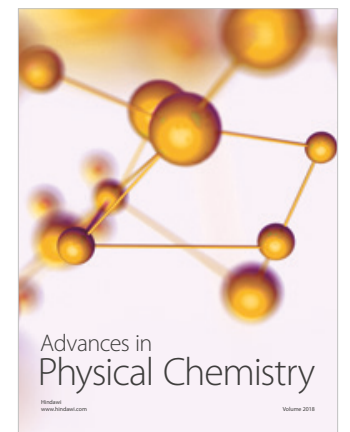

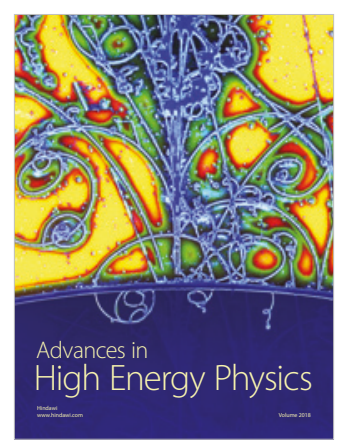

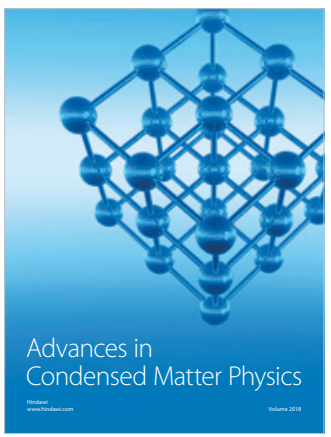

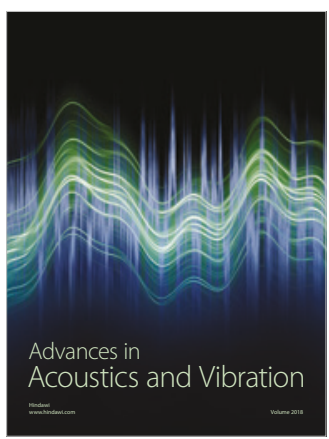

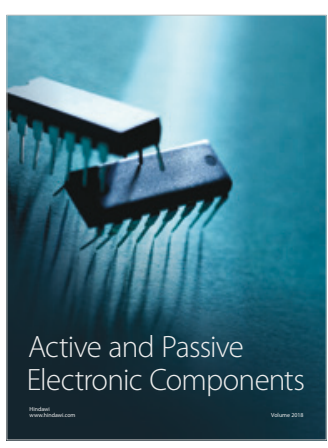
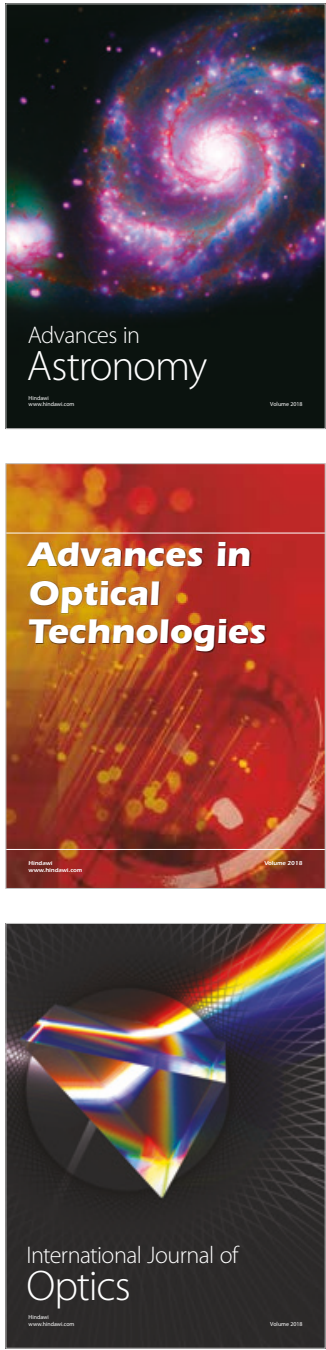